\title{
Knowledge Shared is Power: Utilizing Knowledge Management Activities to Replicate Lean Sigma Best Practices
}

\author{
Dennis C. Chen* \\ Department of Decision Science and Information Systems, Gatton \\ College of Business and Economics, University of Kentucky, 550 \\ South Limestone Street, Lexington, Kentucky, 40506-0034, USA \\ E-mail: dennis.chen@uky.edu \\ *Corresponding author

\section{Clyde W. Holsapple} \\ Department of Decision Science and Information Systems, Gatton \\ College of Business and Economics, University of Kentucky, 550 \\ South Limestone Street, Lexington, Kentucky, 40506-0034, USA \\ E-mail: cwhols@email.uky.edu
}

\begin{abstract}
Lean Sigma programs produce localized gains within corporations. The knowledge generated by these local successes should be manipulated by the organization, so that the gains can be replicated, and savings multiplied across the organization. However, why does knowledge often fail to be successfully manipulated within an organization? This paper discusses a case study analysis in knowledge manipulation activities of a multi- national consumer products company through the lens of the Knowledge Management (KM) Ontology. We then identify and document common obstacles, and offer potential solutions.
\end{abstract}

Keywords: Lean Sigma, Knowledge Manipulation, Knowledge Replication, Knowledge Management Ontology.

Biographical notes: Dennis C. Chen is a Ph.D. student studying Operations Management and Supply Chain Management in the DSIS department of the Gatton College of Business and Economics at the University of Kentucky. He holds a MBA degree from Baylor University and a BE degree in mechanical engineering from Vanderbilt University. He has seventeen years of operations and supply chain experience within multinational public corporations. His current research interests include lean manufacturing and six sigma, knowledge management, and supply chain management.

Clyde W. Holsapple holds the University of Kentucky's Rosenthal Endowed Chair in Management Information Systems and is Professor of Decision Science and Information Systems. He has been recognized as Computer Educator of the Year by the International Association for Computer Information Systems, honored with the University of Kentucky Chancellor's Award for Outstanding Teaching, and recipient of the $R \& D$ Excellence Program Award presented by the Governor of Kentucky. His publication credits include more than a dozen books and 150 articles in journals and books, plus many conference proceeding papers. Professor Holsapple is Editor-in- 


\begin{abstract}
Chief of the Journal of Organizational Computing and Electronic Commerce. He has served in editorial positions for such scholarly journals as Decision Support Systems, Decision Sciences, and Management Science, as a tenured faculty member at the University of Illinois and at Purdue University, and as Director of the Kentucky Initiative for Knowledge Management since its inception in 1988. His B.S. (mathematics), M.S. (computer science), and Ph.D. (management science) degrees are from Purdue University.
\end{abstract}

\title{
1. Introduction
}

Would it not be useful for organizations to capture successes from knowledge generated internally and share these successes between factories and across divisions? Cost savings knowledge generated in one factory through Lean Sigma activities should be replicated in other factories throughout the organization. Knowledge should be appropriately manipulated and shared. Cost savings should be consistently multiplied.

So, do Lean Sigma organizations often fail to successfully manipulate knowledge within their own company? If so, why is this the case and what can be done about it?

We examine these questions through a retrospective analysis of a multi-national consumer products company. The Knowledge Management Ontology (Holsapple \& Joshi, 2005) serves as a framework for considering this firm's knowledge manipulation activities and the managerial actions that influence them. The primary knowledge management manipulation activities are defined in the ontology as Acquisition, Generation, Selection, Assimilation, and Emission. As well, the KM ontology identifies four management influences - Leadership, Control, Coordination, and Measurement. Both the knowledge manipulation activities and the managerial influences on them are evaluated in context of this case study company.

Realistically, companies fail to successfully manipulate knowledge internally for numerous reasons. For starters, company cultures often counteract knowledge management activities (Kayworth \& Leidner, 2003). Closed, professional and joboriented company cultures can stifle knowledge manipulation activities. Conversely, open, parochial, and employee-oriented cultures invigorate knowledge manipulation activities. We analyze the culture present in the case study firm later in the paper.

On the other hand, management activities influence what happens within and across episodes comprised of some pattern of knowledge manipulation activities. Such influences could be sparse or non-existent (Holsapple \& Joshi, 2005). Knowledge leadership, knowledge coordination, knowledge control, and knowledge measurement could individually be missing or could all be missing. We analyze this managerial behavior in our case study as well.

Alternatively, the company may not value or treat knowledge as an asset. Many companies may not recognize the Knowledge Based Theory of the Organization (KBT) (Connor, 1991, Kogut et al, 1992, Grant, 1996, Nonaka, 1994) or even that they compete in a knowledge economy. These companies view their assets as physical assets or financial assets, and do not recognize knowledge as an asset, much less their greatest source of competitiveness.

Whatever the reason may be that companies do not successfully manipulate knowledge assets, the case study provides examples of good practices. We detail a case 
study of one large multi-national consumer product company and dissect the knowledge manipulation activities in its implementation of a Lean Sigma program.

The remainder of the paper is organized as follows. Section 2 briefly describes the case study company and its implementation of a Lean Sigma program. Section 3 examines the five knowledge manipulation activities as they relate to the case study company. Section 4 then examines the four managerial influences as they relate to the case study company. Finally, Section 5 concludes the paper with a discussion of its contributions, limitations, and potential future research.

\section{Case Study: The Lean Sigma Program in a Multi-National Consumer Product Company}

The case study involves a multi-national consumer product company that manufactures a large number of consumer products in various divisions throughout the world. It employs tens of thousands of employees, and has annual sales in the billions of U.S. dollars. The company has launched Lean Sigma activities based on the combination of Lean techniques (Womack \& Jones, 1991) and Six Sigma (Define, Measure, Analyze, Implement, and Control, DMAIC) techniques originated from the Motorola Company. Many black belt engineers (BBs) and green belts (GBs), (engineers technicians, and managers) learned the Lean Sigma tools, and each black belt is held accountable to provide annual costs savings activities generating a multiple of his or her salary (including overhead costs).

Not surprisingly, the black belts and green belts at different factories often work on similar problems, as factories making similar products or variations of similar products often share the same manufacturing and quality challenges. Therefore, redundancies in cost savings efforts are inherent in the organization. Often times, managers acknowledge these redundancies, yet the managers allow the redundancies to continue. Why? Since upper management holds factory management responsible for their bottom line profits and losses, local factory managers often believe they cannot wait for solutions to develop elsewhere then later be duplicated later in their factory. Internal competition between factories fiercely pervades the corporate culture, so that managers simultaneously, and sometimes unknowingly, seek identical cost savings with the highest returns projects at multiple factories.

The Master Black Belt (MBB), who has expertise in the knowledge and use of Lean Six Sigma methods, is responsible for training all black belts throughout the organization on the successful use of these tools. The green belts also receive a subset of training that the black belts receive, but outside local consultants provide the green belt training, since the master black belt does not have enough time to conduct all green belt training in addition to training the black belts. Therefore, external consultants (approved by the master black belt) conduct the green belt training with the help of the black belts located at that factory.

\section{Primary Knowledge Management Manipulation Activities}

The primary knowledge manipulation activities discussed in the KM Ontology are as follows: 


\author{
1. Knowledge Acquisition \\ 2. Knowledge Generation \\ 3. Knowledge Selection \\ 4. Knowledge Assimilation, and \\ 5. Knowledge Emission.
}

While the multi-national corporation in our case study certainly does not explicitly identify each of these primary knowledge manipulation activities, the company coincidentally achieves all but one of the knowledge management manipulation tasks.

We look at each of these knowledge management manipulation activities in detail and highlight knowledge management activities that the multi-national company "completed" with respect to its lean sigma initiative.

\title{
3.1. Knowledge Acquisition
}

The multi-national corporation in the case study specifically sought out a Master Black Belt consultant from outside the organization to lead the Lean Sigma efforts. The Master Black Belt originally led implementation of a pilot program in one of the company's factories. The company required this knowledge acquisition because there was not existing knowledge within the organization on Lean Sigma methods. While the knowledge could have been researched and developed through trial and error, the company chose to acquire these skills, talents, and tacit knowledge from an experienced Master Black Belt. The knowledge acquisition proved invaluable and the quickest and most definite path to obtaining knowledge.

As well, the company displayed knowledge acquisition when local consultants were recruited to help with Green Belt training and to individually coach the newly formed Black Belts. Why were additional consultants needed? Certainly, the company recognized knowledge was available in the organization through the newly hired Master Black Belt. However, the Master Black Belt could not disseminate the knowledge throughout the organization as quickly as needed. Therefore, the company contracted local consultants (who were interviewed and approved by both the Master Black Belt and local factory management) to speed the dissemination of knowledge within the organization.

Therefore, the multinational company utilized specific knowledge acquisition tactics to 1. Acquire knowledge that was non-existent in the organization, and 2. To supplement the newly acquired knowledge to build a critical mass large enough to disseminate knowledge quickly through the organization.

\subsection{Knowledge Generation}

Knowledge generation began in the case study with the Master Black Belt conducting a global training session for newly appointed Black Belts. The Master Black belt asked each factory manager to designate 2-3 black belts trainees from within their engineering group. These typical Black Belts were senior project engineers generally well respected by their technical peers. The local plant manager chose each of the future Black Belts and dedicated $100 \%$ of the Black Belts' time to the Lean Sigma initiative. The Black Belts then attended a global training session conducted by the Master Black Belt. This training is described in more detail in the assimilation section. 
The black belt trainees returned to their respective factories and began collecting and prioritizing cost saving opportunities. Each BB selected one project and completed the Define and Measure Phase prior to their second training with the Master Black Belt. Each BB also summarized and prioritized all potential projects. The BBs generated knowledge themselves by compiling such a list. As the BBs made progress through the Define and Measure phases, the BBs continued to generate knowledge. Finally, by sharing what they learned at training with their colleagues and managers at each factory, the BBs generated knowledge for the organization.

BBs used standard (and agreed upon by the MBB and $\mathrm{BB}$ ) forms and templates to capture the knowledge that was being gathered. The BBs codified each list of potential projects. As well, the BBs shared the progress of the selected projects on company intranets available so that other factories could examine and review the findings. BBs and GBs were beginning to define and measure problems. BBs initially collected data to quantify the problem and potential cost savings. Through data collection, BBs and managers better understood the size and scope of the many of the problems. Data collection combined with analysis often generates knowledge.

Of course, some Black Belts were slow to share their information and analyses with other BBs, and some data collection and analyses were incomplete. As well, many BBs from different factories across the organization chose similar projects, as each factory is looking to maximize its own efficiency and maximize cost reduction. At this early point in the Lean Sigma initiative, local management and the Master Black Belt allowed the duplication in order to build momentum in the Lean Sigma project. Only time would tell if this duplication of effort was wise or not.

The MBB continued to visit each of the various factories to train management, to coach the BBs at that factory, and to interview and help select a local consultant that will in turn train the various green belts at each factory. The training is once again discussed in more detail in the assimilation section.

\subsection{Knowledge Selection}

Time passed and the training continued with the BBs. The MBB taught a week-long training on Analyze, then, the BBs returned to their respective factories to continue to work on their projects. The BBs returned for additional week of training on Implement, and then on Control. Some BBs moved quickly on their project, implemented solutions, and began working on the control phase of their first project. Some BBs trailed behind on the Define and Measure Stage.

BBs who progressed quickly through their first project, they continued to create knowledge by writing up their findings in the standard DMAIC reports. However, the BBs also began the Knowledge Manipulation Activity of selection. The BBs and the local factory management scoured the knowledge that has already been created at their factory and at other factories. BBs posted many of the early projects on the intranet. In addition to the selected projects, BBs posted the lists of potential projects on the intranets. BBs measured the successes of each of the completed projects and quantified their cost savings.

The Knowledge Selection begins. BBs and local managers decide on which project should be started next by the BBs. In fact, earlier projects started by BBs may have been halted, once new knowledge becomes available. Possibly a project that has been completed quickly at another factory can be started and completed quickly at this factory. 
Knowledge Selection becomes a more important knowledge manipulation activity as more knowledge becomes available in the organization. Initially, when the MBB had not generated and/or assimilated much knowledge through training, and when BBs had not generated much knowledge through project definition and measurement, Knowledge Selection was not as important a knowledge manipulation activity. However, as the repository of codified knowledge grows, and as the network of tacit knowledge sharing grows, then knowledge selection becomes ever more critical a knowledge manipulation activity.

\subsection{Knowledge Assimilation}

Knowledge assimilation, as defined by the KM ontology, alters one or a number of the company's knowledge resources, resulting in learning. Knowledge assimilation and knowledge generation are quite similar. However, in terms of replicating lean sigma successes in other factories, the replication falls in the category of knowledge assimilation. The company is able to assimilate knowledge that already exists and reapply learnings to a different arena.

Knowledge assimilation occurred in the BB training that was briefly discussed in the paper. The company flew approximately 20-30 black belts from around the world to a central location for one week training with the Master Black Belt. While this initial training was for one week (Monday-Friday), the complete series of training consisted of approximately four more training sessions each several weeks apart (4-6 weeks between each training). During each stage of the training, the Master Black Belt would train the future BBs on various tools of each stage of the Six Sigma process (D-M-A-I-C). For example, the first week of training focused on an overview of the DMAIC process, and then on specific tools for the D- phase and the M-phase (the Define Phase and the Measure Phase).

Knowledge assimilation occurred during the management and green belt training discussed briefly in earlier sections. But how much of the knowledge was codified? How much was shared through the company intranets? For example, none of the management training material was made available to the local management teams prior to the training? Why? Was it fear that the training would be less effective or less relevant if the knowledge was shared ahead of time to the managers? Was it because the knowledge being shared was not easily codified, but instead tacit knowledge? These are all good questions and opportunities for improvement in future implementations by other companies.

As well, knowledge assimilation happened quite often in the form of a final report. The BB would write the final report after completing the control phase of his or her project. The final report followed a standard form and format that the MBB dictated. Once the final report was complete, the BB would post the report on the company intranet, thus sharing and assimilating the knowledge to the rest of the organization.

Often, the original final report would be written in the local language of the factory. This caused a problem, as many international factories would have to delay reading the report until the report could be translated by someone within the company. The BB might choose to write the original final report in his/her own language to save time and move on to the next cost savings project, or possibly because his/her English skills were not proficient enough. Either way, the fact that the report was not in a language easily accessible for other factories would cause delay in replication of processes and results. 
As well, knowledge assimilation occurred as BBs and mangers gain experience through successful projects as well as projects which fail. Knowledge that may have been available from the early beginning now begins to make sense. Through knowledge assimilation, BBs, managers, and the MBB continue to improve the system. New waves of BBs are trained, GB training is enhanced, and project selection and all phases of the DMAIC process are improved.

While success may have been substantial in one factory, knowledge may need to be modified in order to be applicable in a new factory. Equipment and processes may differ slightly. As well, managers may recognize that the culture present within a local factory may not facilitate the same solutions. Sometimes, a "not invented here" (NIH) syndrome will be in effect. In the case of $\mathrm{NIH}$, managers and engineers reject the proposed solution, saying that it will not work in their factory. Managers will then spend time researching different solutions and creating further delays in cost savings.

\subsection{Knowledge Emission}

Knowledge emission is defined by the KM Ontology as knowledge projections released into the environment. In the external environment sense, the case study company did not emit knowledge outside the company. Certainly, knowledge management security and control issues need to be taken into account. (Jamieson and Handzik, 2004). However, intentional emission of knowledge by our case study company was non-existent.

\subsection{Summary of Knowledge Manipulation Activities}

While the case study company displayed many of the knowledge manipulation activities described in the KM Ontology, it may be difficult to pull out all of the activities from the discussion. Therefore, we have created a table that lists the best practices and obstacles faced by the case study company. Table 1 discusses these best practices and obstacles faced as broken out by KM activity.

Table 2 takes each of these potential obstacles in Table 1 and proposes solutions for each obstacle. 
Table 1: Knowledge Manipulation Activities Best Practices and Obstacles

\begin{tabular}{|c|c|c|}
\hline KM Activity & Best Practice & Obstacles \\
\hline Acquisition & $\begin{array}{l}\text { 1. Hiring (Acquiring) a Master } \\
\text { Black Belt to lead the Lean Sigma } \\
\text { activities in the organization. } \\
\text { 2. Supplementing the MBB } \\
\text { knowledge with local consultants } \\
\text { who can help deliver Green Belt } \\
\text { Training and coach new trained BB. }\end{array}$ & \\
\hline Generation & $\begin{array}{l}\text { 1. The new formed BB then return } \\
\text { to their respective factories to collect } \\
\text { and prioritize cost savings projects, } \\
\text { then completes the Define and } \\
\text { Measure phases of DMAIC process. } \\
\text { This generates knowledge as well. } \\
\text { 2. Common format and structure for } \\
\text { each report. (DMAIC) are utilized } \\
\text { and shared on company intranets. }\end{array}$ & $\begin{array}{l}\text { 1. No time for formal } \\
\text { write up. BB and GB } \\
\text { want to or are asked to } \\
\text { move on to next savings } \\
\text { project. }\end{array}$ \\
\hline Selection & $\begin{array}{l}\text { 1. Company repository of success } \\
\text { stories, often stored on a company } \\
\text { website, with information stored in } \\
\text { easily accessible and reusable } \\
\text { formats (e.g. .doc, .xls, or .ppt } \\
\text { formats.) }\end{array}$ & $\begin{array}{l}\text { 1. Easier to contact } \\
\text { individual directly versus } \\
\text { looking up information on } \\
\text { intranet }\end{array}$ \\
\hline Assimilation & $\begin{array}{l}\text { 1. MBB conducting global } \\
\text { Training of BB to generate } \\
\text { knowledge in the new BB by sharing } \\
\text { of knowledge. } \\
\text { 2. Assimilation occurs naturally } \\
\text { with experience. As BB and } \\
\text { managers gain experience, unused } \\
\text { but useful knowledge that has long } \\
\text { been available become more easily } \\
\text { recognizable and accessible. } \\
\text { 3. Creation of a final report that was } \\
\text { placed on the company intranet and } \\
\text { released into the internal } \\
\text { environment for consumption. }\end{array}$ & $\begin{array}{l}\text { Not Invented Here (i.e. } \\
\text { that solution will not work } \\
\text { here) } \\
\text { Original work and } \\
\text { documents in foreign } \\
\text { language }\end{array}$ \\
\hline Emission & $\begin{array}{l}\text { No external knowledge emission for } \\
\text { our case study company. }\end{array}$ & $\begin{array}{l}\text { Do need to consider } \\
\text { management security and } \\
\text { control issues (Jamieson } \\
\text { and Handzik 2004) }\end{array}$ \\
\hline
\end{tabular}


Table 2: Obstacles and Proposed Solutions

\begin{tabular}{|l|l|}
\hline \multicolumn{1}{|c|}{ Obstacles } & \multicolumn{1}{c|}{ Potential Solution } \\
\hline $\begin{array}{l}\text { No time for formal write up. BB and GB } \\
\text { want to or are asked to move on to next } \\
\text { savings project. }\end{array}$ & $\begin{array}{l}\text { Mandatory requirement to summarize key } \\
\text { learnings to share knowledge with other } \\
\text { internal groups }\end{array}$ \\
\hline $\begin{array}{l}\text { Easier to contact individual directly versus } \\
\text { looking up information on intranet }\end{array}$ & $\begin{array}{l}\text { Informal networks are certainly acceptable } \\
\text { means of obtaining knowledge. }\end{array}$ \\
\hline $\begin{array}{l}\text { Not Invented Here (i.e. that solution will } \\
\text { not work here) }\end{array}$ & $\begin{array}{l}\text { Management must provide leadership in } \\
\text { establishing a culture that minimizes NIH } \\
\text { syndrome. }\end{array}$ \\
\hline $\begin{array}{l}\text { Original work and documents in foreign } \\
\text { language }\end{array}$ & $\begin{array}{l}\text { Translators dedicated to the lean sigma } \\
\text { program would be a potential solution. Of } \\
\text { course, requiring the BB to struggle } \\
\text { through writing reports in English might be } \\
\text { useful learning and skill building as well. }\end{array}$ \\
\hline
\end{tabular}

\section{Secondary Knowledge Management Managerial Influences}

The KM Ontology defines each of the knowledge management managerial influences as follows:

1. Knowledge Leadership

2. Knowledge Coordination

3. Knowledge Control, and

4. Knowledge Measurement.

We describe how the case study multi-national company addresses each of these managerial influences in detail and summarize them in Table 3.

\subsection{Knowledge Leadership}

The KM Ontology describes knowledge leadership as management's ability to create a culture where knowledge processors can most effectively conduct knowledge work. We look at leadership from the more interesting view of local factory managers, then from the view of the MBB.

Looking at the viewpoint of the local factory mangers, many of the plant managers fell short of providing such a culture. Much of the lean sigma efforts would be considered a change project. Many plant managers were reluctant to offer two valuable senior engineers as $100 \%$ dedicated to being BBs. As well, many managers believed the lean sigma program as a "flavor of the month" program that would disappear within a year or so.

The MBB as well fell short of providing the leadership needed. The MBB delivered the training to the BBs, but also training to the management teams at each factory. The MBB needed to convince each of the factory managers that the lean sigma program would require the plant manager's skills in developing a knowledge sharing culture. 
Potentially, the MBB fell short of providing the message, or quite possibly, senior management fell short of providing the message to the plant managers as well. In any case, knowledge leadership was lacking from the standpoint of our case study company.

\subsection{Knowledge Coordination}

Knowledge coordination was more evident in the case study company. The MBB often tried to create opportunities for the knowledge resources (BBs and GBs) to communicate within the company. The company intranet provided project summaries, project templates, training materials that had been used in BB training or GB training. Potential project lists were also shared from factory to factory.

Knowledge coordination may have been lacking within a factory. The BB or the engineering manager may be the only resources tapped into the company network. Extending the network to local green belts or local staff may have sparked ideas for other cost savings ideas and quicker replication of successful project in other factories.

\subsection{Knowledge Control}

Knowledge control falls into two main areas in the KM Ontology. The first area of knowledge control ensures that adequate knowledge resources and processors are available in sufficient quality and quantity. The second area of knowledge control discusses the security of knowledge resources within the company. Let's look at each of these areas specifically for our case study company.

Regarding adequate knowledge resources and processors, our case study company provided the required number of BBs and GB's as needed by the MBB. Certainly, the company supported the local management training and provided the required local contractors involved in training the GBs. Therefore, from the standpoint of the first area of Knowledge control, the case study company met the requirements.

Regarding security of the knowledge resources, the case study company also provided adequate security on the intranet and of knowledge being handed out at the training. While such information could have made it to external competitors, managers and employees were bound by the standard confidentiality agreements in each employee contract.

\subsection{Knowledge Measurement}

Knowledge management encompasses the company's efforts to gage and evaluate its knowledge processors, knowledge resources, knowledge manipulation activities, managerial influences, knowledge management episodes, and overall knowledge management activities. This measurement is quite lofty, and our case study company would generally fall short in each of these areas of measurement.

While the main activity was lean sigma, the MBB did not explicitly identify the knowledge management activities. Therefore, the MBB did not measure the KM manipulation activities, nor the overall knowledge management activities. However, each $\mathrm{BB}$ was evaluated on his/her performance during the training and during their first project. Once the BB successfully completed the training and successfully completed a certain financial return in the project, the MBB awarded internal certification to the $\mathrm{BB}$. This internal certification provided some form of measurement of the BBs lean sigma skills and abilities.

As well, the MBB gave feedback to the local plant management regarding their role in supporting the lean sigma activities. While the feedback was not specifically aligned 
with the managerial influences, the feedback did cover many of the areas of managerial influences.

Table 3: Knowledge Managerial Influences Best Practices and Obstacles

\begin{tabular}{|c|c|c|}
\hline $\begin{array}{l}\text { KM Managerial } \\
\text { Influences }\end{array}$ & Best Practice & Obstacles \\
\hline Leadership & $\begin{array}{l}\text { Create a culture where } \\
\text { knowledge processors can most } \\
\text { effectively conduct knowledge } \\
\text { work. } \\
\text { (Limited examples in case study } \\
\text { company) }\end{array}$ & $\begin{array}{l}\text { - Unwillingness of factory managers } \\
\text { to provide dedicated resources (BBs) } \\
\text { "Program of the Month" mentality } \\
\text { does not support initiative but } \\
\text { instead waits for program to fail } \\
\text { - Failure of MBB/Senior management } \\
\text { to communicate culture } \\
\text { building/nurturing role of factory } \\
\text { managers }\end{array}$ \\
\hline Coordination & $\begin{array}{l}\text { Create opportunities for } \\
\text { knowledge resources to } \\
\text { communicate within the } \\
\text { company. } \\
\text { - Centralized BB training } \\
\text { - } \quad \text { Intranet to share project } \\
\text { summaries, templates, } \\
\text { training materials } \\
\text { - Sharing of potential project } \\
\text { lists / savings calculations }\end{array}$ & $\begin{array}{l}\text { - Limited access to intranet within } \\
\text { factory (only BBs and engineering } \\
\text { manager) } \\
\text { GB and other factory staff only } \\
\text { networked within factory and not } \\
\text { between factories }\end{array}$ \\
\hline Control & $\begin{array}{l}\text { Ensure adequate knowledge } \\
\text { resources and processors are } \\
\text { available in sufficient quality and } \\
\text { quantity. } \\
\text { Ensure security of knowledge } \\
\text { resources within the company. } \\
\text { - Use of consultants/ } \\
\text { contractors to supplement } \\
\text { knowledge resources } \\
\text { Use of confidentiality } \\
\text { agreements to provide } \\
\text { security of knowledge } \\
\text { resources }\end{array}$ & \\
\hline Measurement & $\begin{array}{l}\text { Gage and evaluate knowledge } \\
\text { processors, resources, activities, } \\
\text { episodes, etc. for effectiveness. } \\
\text { (Limited examples in case study } \\
\text { company) }\end{array}$ & $\begin{array}{l}\text { - KM not identified as part of Lean } \\
\text { Sigma program for case study } \\
\text { company. Therefore no measures } \\
\text { were identified by MBB }\end{array}$ \\
\hline
\end{tabular}




\section{Conclusions}

This article analyzes a case study company in its efforts in implementing and replicating lean sigma best practices across its many factories. Specifically, lean sigma activities are juxtaposed against the five primary knowledge manipulation activities and the four secondary knowledge managerial influences as outlined in the KM Ontology. A case study of a multi-national consumer products company is used to study each of these primary and secondary KM activities.

We find that while the case study company did not explicitly integrate KM with their lean sigma activities, naturally, there was overlap. Four of the five primary KM manipulation activities were addressed by the case study company. However a large portion of the supporting managerial influences were left unnoticed.

The limitation of a case study is that it is only one data point. Many conclusions may not be applicable to other companies or industries. As well, the integration of lean and six sigma programs into one program may differ from other company implementation. However, case studies can offer insight into potential experimental designs. Additional case studies should be evaluated and more empirical research is needed in the area of successful strategies of Lean Sigma and Knowledge Management implementation.

The study only scratches the surface of how to integrate KM activities with lean sigma programs. Companies looking at either of these initiatives, Knowledge Management or Lean Sigma, would do well to study them both collectively. By combining these two initiatives of KM and lean sigma, companies will truly be able to gain the power of shared knowledge.

\section{References}

1 Bennet, A., \& Bennet, D. (2004). The Rise of the Knowledge Organization. Handbook on Knowledge Management 1, Springer-Verlag, Belin Heidelberg, 3-20.

2 Conner, K.R. (1991). A Historical Comparison of the Resource-Based Theory and Five Schools of Thought Within Industrial Organization Economics: Do We Have a New Theory of the Firm? Journal of Management, 17(1), 121-154.

3 Grant, R.M. (1996). Toward a Knowledge-Based Theory of the Firm. Strategic Management Journal, 17, Winter Special Issue, 109-122.

4 Grant, R.M. (1996). Prospering in Dynamically-Competitive Environments: Organizational Capability as Knowledge Integration. Organization Science, 7(4), 375-387.

5 Holsapple, C., \& Joshi, K.D. (2005). A Formal Knowledge Management Ontology: Conduct, Activities, Resources, and Influences. Journal of the American Society for Information Science and Technology, 55(7), 593-612.

6 Jamieson, R., \& Handzic, M. (2004). Framework for Security, Control and Assurance of Knowledge Management Systems. Handbook on Knowledge Management 1, Springer-Verlag, Belin Heidelberg, 477-505. 
7 Kayworth, T., \& Leidner, D. (2004). Organizational Culture as a Knowledge Resource. Handbook on Knowledge Management 1, Springer-Verlag, Belin Heidelberg, 235-252.

8 Kogut, B., \& Zander, U. (1992). Knowledge of the Firm, Combinative Capabilities, and the Replication of Technology. Organization Science, 3(3), 383-397.

9 Kogut, B. (2000). The Network as Knowledge: Generative Rules and the Emergence of Structure. Strategic Management Journal, 21, 405-425.

10 Nonaka, I. (1994). A Dynamic Theory of Organizational Knowledge Creation. Organization Science, 5(1), 14-37.

11 Nonaka, I., \& Takeuchi, H. (1995). The Knowledge-Creating Company: How Japanese Companies Create the Dynamics of Innovation. Oxford University Press, New York.

12 O'Dell, C. \& Grayson, C.J. (2004) Identifying and Transferring Internal Best Practices. Handbook on Knowledge Management 1, Springer-Verlag, Belin Heidelberg, 601-622.

13 Spender, J.C. (1996). Making Knowledge the Basis of a Dynamic Theory of the Firm. Strategic Management Journal, 17, Special Issues, 45-62.

14 Wolford, Dan, \& Kwiecien, S. (2004). Driving Knowledge Management at Ford Motor Company. Handbook on Knowledge Management 2, Springer-Verlag, Belin Heidelberg, 501-510.

15 Womack, J., Jones, D., \& Roos, D. (1990). The Machine that Changed the World. Macmillan, New York. 